\title{
Erratum to: Assessment of the Nucleus-to-Cytoplasmic Ratio in MCF-7 Cells Using Ultra-high Frequency Ultrasound and Photoacoustics
}

\author{
M. J. Moore ${ }^{1,2,3}$ E. M. Strohm ${ }^{1,2,3}$. \\ M. C. Kolios ${ }^{1,2,3}$
}

Published online: 16 February 2017

๑) Springer Science+Business Media New York 2017

\section{Erratum to: Int J Thermophys (2016) 37:118 DOI 10.1007/s10765-016-2129-y}

The acknowledgment section was inadvertently not published in the original publication. The acknowledgment section is given here.

Acknowledgements The authors would like to thank E. Berndl (Ryerson University) for her assistance with biological cell culturing. This research is supported in part by the Natural Sciences and Engineering Research Council of Canada, the Canadian Cancer Society, the Canadian Foundation for Innovation, the Ontario Ministry for Research and Innovation, and the Terry Fox Foundation.

The online version of the original article can be found under doi:10.1007/s10765-016-2129-y.

M. C. Kolios

mkolios@ryerson.ca

1 Department of Physics, Ryerson University, Toronto, ON, Canada

2 Institute for Biomedical Engineering, Science and Technology (iBEST), Ryerson University and St. Michaels Hospital, Toronto, ON, Canada

3 Keenan Research Centre for Biomedical Science, St. Michaels Hospital, Toronto, ON, Canada 